\title{
Early life obesity and chronic kidney disease in later life
}

\author{
Hyung Eun Yim • Kee Hwan Yoo
}

Received: 5 February 2014 /Revised: 23 April 2014 / Accepted: 17 July 2014 / Published online: 22 August 2014

(C) IPNA 2014

\begin{abstract}
The prevalence of chronic kidney disease (CKD) has increased considerably with a parallel rise in the prevalence of obesity. It is now recognized that early life nutrition has life-long effects on the susceptibility of an individual to develop obesity, diabetes, cardiovascular disease and CKD. The kidney can be programmed by a number of intrauterine and neonatal insults. Low birth weight (LBW) is one of the most identifiable markers of a suboptimal prenatal environment, and the important intrarenal factors sensitive to programming events include decreased nephron number and altered control of the renin-angiotensin system (RAS). LBW complicated by accelerated catch-up growth is associated with an increased risk of obesity, hypertension and CKD in later life. High birth weight and exposure to maternal diabetes or obesity can enhance the risk for developing CKD in later life. Rapid postnatal growth per se may also contribute to the subsequent development of obesity and CKD regardless of birth weight and prenatal nutrition. Although the mechanisms of renal risks due to early life nutritional programming remain largely unknown, experimental and clinical studies suggest the burdening role of early life obesity in longstanding cardiovascular and renal diseases.
\end{abstract}

Keywords Childhood obesity $\cdot$ Chronic kidney failure Growth and development · Hypertension · Overnutrition

H. E. Yim • K. H. Yoo

Department of Pediatrics, College of Medicine, Korea University, Seoul 152-703, South Korea

K. H. Yoo $(\bowtie)$

Department of Pediatrics, Korea University Guro Hospital, 148, Gurodong-ro, Guro-gu, Seoul 152-703, South Korea

e-mail: guroped@korea.ac.kr

\section{Introduction}

Much attention has been paid to the growing pandemic of obesity [1]. Chronic kidney disease (CKD) is a major complication of obesity, and the prevalence of CKD has also increased dramatically in parallel with this rise in the prevalence of obesity [2]. Because the rates of cardiovascular disease (CVD), end-stage renal disease (ESRD) and premature death are increased in patients with CKD [3], it is essential to recognize risk factors for the development and progression of this disease. Among these, obesity is a definite modifiable risk factor for the progression of CKD, while many complex factors, such as genetic, metabolic and environmental conditions, are responsible for the predisposition to obesity [2].

A concept which has become more widely acceptable in recent years is that of developmental programming of adult chronic diseases, which implies that alterations in the intrauterine and early postnatal environments can permanently change the structure and function of various systems and cause predisposition to the development of disease later in life [4]. In 1989 Barker and colleagues reported an inverse relationship between low birth weight (LBW) and the increased rate of mortality due to coronary heart disease [5], and subsequent studies confirmed an increased risk for the development of hypertension (HTN), type 2 diabetes, CVD and CKD across the timespan of fetal and early childhood development $[4,6,7]$. Experimental and clinical data have demonstrated a critical impact of increased weight gain and fat deposition during neonatal life on life-long increased risk of obesity [8-10]. A longstanding effect of postnatal nutrition and/or postnatal growth on cardiovascular, metabolic and renal functions has also been found, particularly in rodents [10]. In this review we address the current understanding of developmental programming of CKD with a particular focus on the effects of early growth and nutrition. 


\section{Renal programming}

Nephrogenesis in rodents continues after birth up to postnatal days 7-10, whereas nephrogenesis in humans is achieved by gestational weeks 34-36. Unlike most organs in which cell proliferation occurs before the third trimester, $60 \%$ of the nephron population is formed during the third trimester of pregnancy, with nephron formation stopping in normal pregnancies at 36 weeks of gestation [11]. Therefore, interference with third trimester fetal growth would impair nephron development [12, 13]. However, postnatal renal maturation also persists after birth, including increases in glomerular size and tubular length, with involvement of the renal renin-angiotensin system (RAS) [14]. Maturation of the sodium and water reabsorption systems in tubules is thought to take up to 18 months in human kidneys [15] and 6 weeks in rodent kidneys [16]. Given the timing of rapid maturation of human kidneys postnatally, one must also take into account that the kidney may be sensitive to renal programming ex utero, as has been shown in rodents [17]. LBW is one of the most identifiable markers of a suboptimal prenatal environment, and the important intrarenal factors sensitive to programming events are nephron endowment, the RAS, tubular sodium handling and the renal sympathetic nerves [18].

Birth weight and nephron number

Approximately 25 years ago, Brenner et al. [19] suggested that a congenital reduction in nephron number could explain why some individuals are more vulnerable to HTN and renal injury than others. A low nephron number causes a decline in the filtration surface area, resulting in salt retention, elevated blood pressure (BP) and reduced renal adaptive capacity in the clinical setting of injury. This theory led to the proposal of a possible association between an increased prevalence of HTN and a high frequency of renal disease in subjects of LBW, whereby LBW was anticipated to be related to a decreased number of nephrons [12]. A maternal low protein diet, vitamin A or iron deficiency, uterine artery ligation or maternal gestational exposure to glucocorticoids usually result in intrauterine growth restriction (IUGR) and a decrease in nephron number by $20-50 \%[11,13,20]$. Maternal gestational diabetes can also affect fetal nephrogenesis in rodents [21]. Hinchliffe et al. [22] observed that infants with asymmetric IUGR had a significant decrease in nephron numbers at a birth weight of less than the third percentile. Hughson et al. [23] applied stereologic techniques to kidneys obtained at autopsy and showed a direct linear relationship between total glomerular number and birth weight in adult and fully developed postnatal kidneys of children. However, the correlation between birth weight and nephron number is not always linear, and it may be difficult to predict nephron endowment for an individual based only on birth weight [24]. Moreover, a low nephron number alone can be insufficient to mediate "fetally programmed" renal disease and CVDs [12, 14]. In the case of moderately decreased nephron number, HTN and CKD can increase in the presence of additional factors, such as enhanced sodium or protein intake $[14,25]$.

\section{Role of the RAS}

The RAS is active during the perinatal period and is a pivotal factor for normal kidney development [26, 27]. Numerous studies have shown that interrupting the RAS during nephrogenesis results in abnormalities in renal structure and function [27]. In the neonatal rat, the inhibition of angiotensin II expression reduces the renal expression of critical growth factors, which may account for renal growth impairment [28], and RAS blockade decreases cellular proliferation, increases apoptosis and modulates the expression of the mitogenactivated protein kinase family in the kidney [29]. Inhibiting angiotensin II also induces impaired cardiac growth in developing rats by decreasing the proliferation and apoptosis of myocytes [30].

Thus, it is not surprising that the perinatal RAS plays an important role in long-term renal physiologic regulation and, indeed, in terms of total nephron endowment, the RAS has been implicated in "fetally programmed" renal disease and CVDs [14, 18]. Vehaskari et al. [31] found that perinatal protein restriction in the rat suppressed the newborn intrarenal RAS, reduced the number of glomeruli and induced glomerular enlargement and HTN in the adult rat. In this study, protein expression of angiotensin II type 1 (AT1) and AT2 receptors decreased on day 1 but increased on day 28 in the kidneys of offspring from low-protein pregnancies, suggesting that prenatal programming of HTN is associated with an abnormal pattern of intrarenal RAS ontogeny that may play a pathogenetic role by constitutively altering renal hemodynamics or sodium reabsorption [31]. Woods et al. [32] reported that altered neonatal intrarenal RAS expression was associated with higher glomerular filtration rate (GFR) per nephron compared with that in the control group, indirectly suggesting that glomerular hyperfiltration at the single-nephron level was present. Inhibiting the RAS during development also results in a reduced number of nephrons, HTN, albuminuria, glomerulosclerosis, renal interstitial inflammation and creatinine retention in these offspring in adulthood [33]. Moreover, our recent data show that altered intrarenal RAS control during renal maturation (increased renin and AT2 receptor activity at 28 days of age) is associated with life-long renal dysfunction in neonatally overfed rats [34-36]. Taken togeth$\mathrm{er}$, these findings suggest abnormal regulation of the perinatal RAS may be responsible for renal impairment in adulthood, which is enhanced with age. 


\section{Early life obesity}

Maternal undernutrition and accelerated catch-up growth

The prenatal and early postnatal period is a critical time to determine long-term body weight [37]. Initial studies on the "fetal origins hypothesis" focused largely on the effects of intrauterine malnutrition and LBW on the subsequent development of insulin resistance and obesity [38]. Experimental and clinical studies have shown that the rate of postnatal growth may be a more important factor in determining the risk of obesity in later life than the absolute body mass index (BMI) at any stage [37, 39]. A mismatch between the pre- and postnatal nutrient environments significantly increases the risk of developing obesity. IUGR infants born into an environment of enhanced nutrition grow rapidly and show increased adiposity throughout their life [37]. Suckling of IUGR pups by ad libitum-fed dams induces accelerated catch-up growth, which is related to an increased percentage of body fat in adulthood and high leptin levels [39]. In contrast, preventing early catchup growth in IUGR or small for gestational age (SGA) offspring may diminish the risk of obesity in later life [39, 40].

\section{Maternal obesity and diabetes}

Researchers have recently begun to focus on the effects of overnutrition during the critical developmental period and the offspring's risk at an older age of having the chronic diseases related to IUGR [41]. It has been shown that increased nutrient availability in utero (e.g. through gestational diabetes or maternal obesity), as well as poor nutrition in early life, enhances the risk of disease in later life, including obesity, impaired glucose tolerance and the metabolic syndrome [42]. Epidemiologic evidence originated in studies on the Pima Indians in whom there is an increased incidence of type 2 diabetes. Both high birth weight and LBW in this population are associated with a greater risk of type 2 diabetes in later life. Of note, macrosomia has been found to be highly associated with a high prevalence of gestational diabetes [43]. It is now known that offspring of mothers with diabetes have up to a tenfold higher risk of becoming obese and developing impaired glucose tolerance as adolescents [44]. Even in non-obese diabetic mothers, offspring are more likely to have increased body fat and to develop obesity in later life [45].

Independent of maternal diabetes, excessive weight gain during pregnancy can also have long-term deleterious effects in terms of increased cardiovascular risks for the offspring [46]. Offspring of obese mothers are more likely to have obesity and metabolic complications, such as insulin resistance and metabolic syndrome in later life [47, 48]. These findings suggest that obese mothers without diabetes may still have metabolic factors that affect fetal growth and postnatal outcome. Perinatally acquired obesity, diabetes and metabolic syndrome may be passed on to succeeding generations and lead to a snowball effect, intergenerational multiplication of obesity and a considerable contribution to the obesity pandemic [49] (Fig. 1). However, the intergenerational transmission of obesity and related chronic diseases is not a simple mechanism, and other factors, such as genetic or ethnic predisposition, gene-environment interaction, dietary and physical activity habits, socioeconomic status and environmental factors, may be determinants of health status at each period of life [50].

Postnatal nutrition (rapid postnatal growth per se)

The immediate postnatal period is critical to development as it is the period of the fastest growth in a lifetime, as well as of tissue and organ development wherein various regulatory mechanisms continue to develop after birth [37]. Therefore, rapid postnatal growth per se immediately post-partum is not only vital for babies born prematurely or SGA but also in those born with a normal birth weight (NBW). Each $100 \mathrm{~g}$ increase in weight gain during the first week of life is associated with a $28 \%$ increase in the risk of becoming an overweight adult, even in children born with a NBW [9]. A recent cohort study confirmed that rapid postnatal growth over the first 2 years of life is associated with BP level, BMI and waist circumference in adulthood, independent of birth weight [51].

Experimental data further support that rapid postnatal growth per se is associated with an increased risk of overweight and obesity in later life. Reducing litter size in rodents after birth induces significant increases in breast milk consumption due to greater availability during the critical postnatal period. Several groups, including ours, have shown that rodents overfed postnatally are overweight at weaning and maintain their body weight gain throughout their lifespan, although the degree and duration of the increase in body weight varies among studies $[34,35,52]$. One of the key elements of overweight in neonatally overfed adult rodents is hyperphagia and increased appetite throughout life [8]. Postnatal overfeeding induces early malprogramming of the hypothalamic-pituitary-adrenal axis, increasing central leptin and insulin resistance and orexigenic signals. Visceral white adipose tissue, lipogenic activities and inflammatory status increase and glucose/insulin homeostasis is impaired in neonatally overfed rodents [10]. Of note, this rapid postnatal growth per se causes early and late modifications in renal and cardiovascular functions in rodents [10, 34-36, 52].

\section{Early life obesity and the risk of CKD}

Low birth weight and prematurity have been traditionally associated with HTN and decreased renal function, which 
Fig. 1 Integrative hypothesis for intergenerational multiplication of obesity and related chronic diseases. Perinatally acquired obesity and its related complications seem to be critical as they can be transmitted to succeeding generations by female offspring

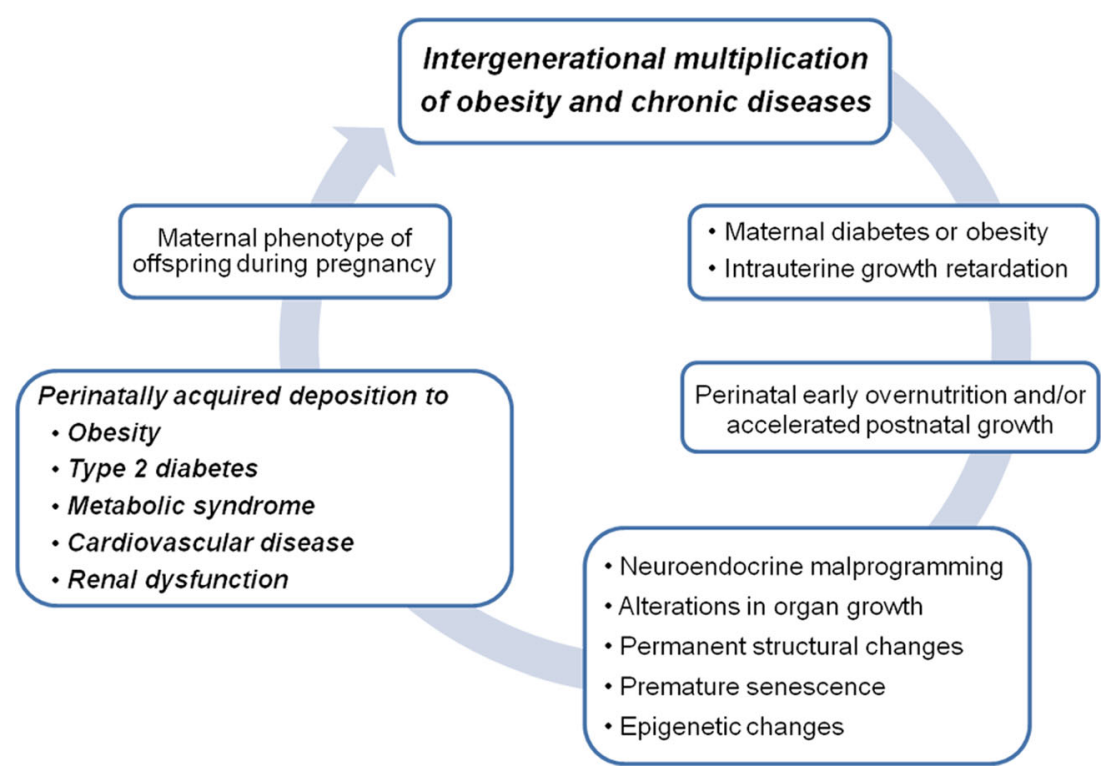

manifests in early childhood and can progress to overt disease later in adulthood. It is now evident that nutrition is the cornerstone of this association [12] and that postnatal factors and rapid postnatal growth per se may also contribute to the pathogenesis and increased risk of obesity and CKD in later life, even independently of birth weight and prenatal nutrition $[35,36,52]$. The mechanisms of renal and cardiovascular risks due to early life nutritional programming remain largely unknown, whereas fundamental biological processes, such as permanent structural changes, accelerated cellular aging and epigenetic regulation, may form integral underlying mechanisms during early life programming [41] (Fig. 1).

\section{Human data}

High birth weight, exposure to maternal diabetes and early postnatal weight gain are risk factors for childhood obesity and can be related to proteinuria and kidney disease in later life [12]. A U-shaped relationship has been shown in population-based studies between birth weight and the risk of CKD, suggesting that high birth weight is as important as LBW for renal programming [53, 54]. Li et al. [53] proposed that among men: (1) LBW, mediated through a low nephron number, is associated with CKD in adulthood and (2) high birth weight, due to its link with maternal and future insulin resistance and HTN, may also be associated with CKD in later life. Vikse et al. [54] confirmed the hypothesis of increased risk for ESRD associated with both a high birth weight and LBW in women. High birth weight also poses a significant risk for developing metabolic syndrome and ESRD caused by diabetic nephropathy later in life $[47,55]$, with children who were exposed to either maternal diabetes or obesity being at a particularly increased risk [47].
Postnatal accelerated weight gain has been related consistently with an increased risk of adult HTN and CVD. In a study of 346 British adults, those born with LBW who had rapid weight gain during early childhood showed the highest BP as adults. Systolic BP increased by $1.3 \mathrm{mmHg}$ [95\% confidence interval (CI) $0.3-2.3$ ] for every standard deviation decrease in birth weight and by $1.6 \mathrm{mmHg}(95 \% \mathrm{CI} 0.6-2.7)$ for every standard deviation increase in early childhood weight gain [7]. Among 216,771 Scandinavian adults, the risk of HTN and CVD was also greatest in children born with LBW who subsequently experienced considerable weight gain[56]. In a study of 80 children with proteinuric renal disease, kidney disease progressed fastest in those who had been premature and subsequently become obese [57]. Two recent studies have also shown that an early high protein diet and rapid postnatal growth tend to induce renal hypertrophy even in healthy infants born at term. In one study, a group of formula-fed infants showed a $25 \%$ increase in renal volume at 3 months of age compared to that in breastfed infants [58], and in a second study, kidney volume in high protein formula-fed infants was $10 \%$ higher than that in breastfed infants at 6 months of age [59]. This renal effect may be attributable to glomerular hyperfiltration at the single-nephron level caused by high protein intake, as confirmed in experimental studies [52]. Recent clinical data have also shown that being overweight throughout early life or becoming overweight during the period from puberty to age 20 years is associated with CKD at age 60-64 years [60]. Taken together, these human studies suggest that nutrition during early life can be critical in determining long-term renal and cardiovascular health. Future experimental animal studies may confirm the burdening role of early life overgrowth in long-standing renal disease and CVDs. 
Experimental studies

In a murine model of maternal diet-induced obesity, the offspring of obese dams fed a palatable obesogenic diet before mating and throughout pregnancy and lactation were hyperphagic in early postnatal life, had increased adiposity and were hypertensive, insulin resistant and heavier in postnatal life [61]. Adequate postnatal nutrition restores low nephron numbers and ameliorates HTN in rats with LBW, whereas postnatal overfeeding after birth induces obesity, HTN, proteinuria and glomerulosclerosis in adulthood in both rats with LBW and NBW [17, 52].

Early postnatal overfeeding or rapid postnatal growth per se in rodents induced by reduced litter size may influence renal and cardiac maturation. In the study of Yim et al. [34], early postnatal overfeeding during the suckling period in young male rats caused the development of hyperleptinemia and overweight and inappropriately stimulated the intrarenal RAS and extracellular matrix-linked molecules during renal growth and development. Ha et al. [62] found increased cellular turnover and inter-ventricular septal hypertrophy with increased activities of renin and the AT2 receptor in the hearts of neonatally overfed young rats. Boubred et al. [52] showed that early postnatal overnutrition induces impaired nephrogenesis and renal maturation in both rats with IUGR and NBW. Early postnatal overfeeding in Wistar rats also causes cardiac hypertrophy at weaning, with a significant increase in ventricular wall thickness, shortening of left ventricular diameter, enlargement of cardiomyocyte area and a decrease in coronary vessel density [63]. These effects might contribute to an abnormal programming of renal and cardiac growth and are presumed to continue during an individual's lifespan. Early postnatal overfeeding results in persistent overweight, increased renal expression of macrophages and inflammatory and pro-fibrotic cytokines, augmented cortical apoptosis and glomerulosclerosis, renal dysfunction and systemic HTN in adult male rats [35]. Associated with these abnormalities, Alcazar et al. [64] reported that early postnatal hyperalimentation in Wistar rats during lactation resulted in decreased GFR, proteinuria and increased renal inflammation, as well as the expression and deposition of extracellular matrix molecules on postnatal day 70 . These authors suggested that the underlying mechanism consisted of intrinsic renal leptin resistance and concomitant upregulated neuropeptide Y expression. It has been shown that leptin and neuropeptide $\mathrm{Y}$ play an important role in BP regulation and that neuropeptide $\mathrm{Y}$ is also involved in the control of energy intake [64, 65].

In adult mice, early postnatal overfeeding modifies the expression of several genes involved in cardiac structural organization, metabolism, vasoreactivity, cell signaling/ communication and oxidative stress. In overfed adult mice, diastolic and systolic BP levels are significantly higher, and there is also left ventricular shortening and ejection fraction decrease [66]. Histological studies show higher collagen density in the ventricular tissues of adult rats which were overfed during the neonatal period [67]. These findings suggest that early postnatal overnutrition or rapid postnatal growth per se may induce permanent changes in the cytoskeletal structure and organization of cardiomyocytes [10].

Moreover, early postnatal overnutrition can enhance and accelerate structural changes of renal aging. Early postnatal overnutrition in 12-month-old male rats leads to systolic HTN, decreased GFR and increased macrophage infiltration, apoptosis, glomerulosclerosis and tubulointerstitial fibrosis in the renal cortex. Neonatally overfed rats had significantly fewer glomeruli and decreased intrarenal renin expression at adulthood than the controls [36]. These findings suggest that early postnatal overnutrition during the suckling period may induce disturbances in renal and cardiac maturation in association with intrarenal and intracardiac RAS dysregulation in young male rats [34, 62]. Altered RAS control beginning in the neonatal stage can malprogram long-standing renal physiologic regulation and BP levels [34-36]. Increased renal workload due to postnatal overnutrition may also provoke glomerular hyperfiltration at the single-nephron level, which in turn can induce glomerulosclerosis, progressive renal dysfunction and HTN [19]. Persistent HTN and glomerulosclerosis can aggravate tubulo-interstitial damage, which may result in accelerated renal aging [36] (Fig. 2).

Taken together, early life obesity can have deleterious effects in terms of the development of CVD and CKD in later life, and the benefits of a balance between perinatal nutrition and early life growth should be carefully evaluated. Studies are still necessary to elucidate the effect of neonatal nutrition and/or neonatal growth on long-term renal disease and CVDs.

\section{Potential mechanisms of early life nutrition programming effects}

Permanent structural changes

Alterations in organ structure are one of mechanisms by which the effects of the early environment could have a permanent effect on tissue function [41]. During the early critical developmental period, short-term structural changes can permanently alter organ development at a time of extreme vulnerability. Overnutrition during the immediate postnatal period in rodents results in early changes in the hypothalamic axis controlling energy homeostasis, circulating concentrations of hormones, functions of several organs and gene expression. These early alterations may modify structural organization and metabolism and make these rodents highly susceptible to chronic pathological conditions [10]. The endocrine component of the pancreas is particularly vulnerable to alterations 
Fig. 2 Renal and cardiovascular programming due to early postnatal overfeeding in rats. Postnatal overfeeding by reducing litter size in rodents induces and maintains body weight gain throughout life. Early disturbances in renal and cardiac maturation due to reninangiotensin system $(R A S)$ gene dysregulation induce progressive renal dysfunction and hypertension $(H T N)$. Persistent HTN and glomerulosclerosis aggravate tubulo-interstitial damage, which can result in the acceleration of renal aging. (ECM Extracellular matrix, GFR glomerular filtration rate)

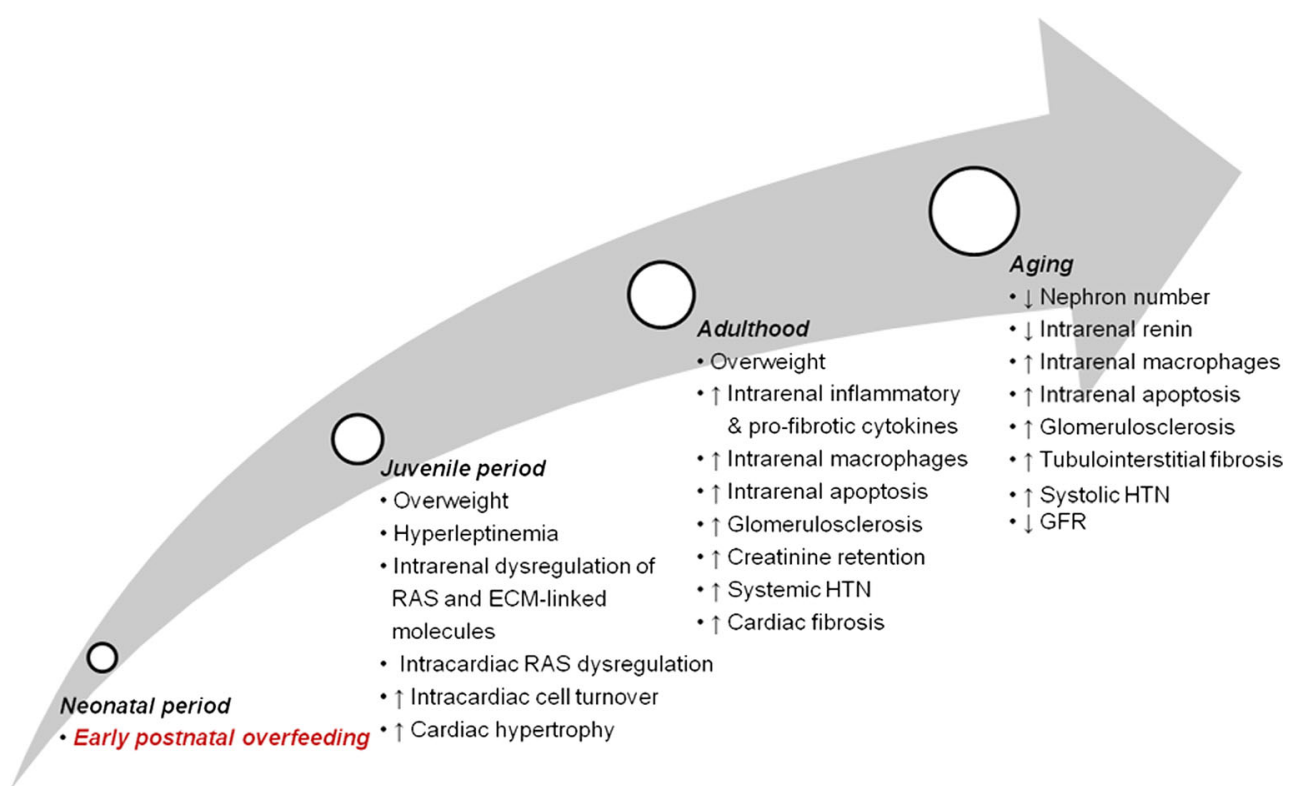

in nutrition during perinatal life that result in permanent changes in its structure [68]. As already mentioned, obesity in early life has immediate and permanent effects on kidney and cardiac structure, as well as on metabolism and functional changes [34-36, 62, 66, 67]. Alterations in the control of the RAS induced by early life obesity seem likely to contribute to these programmed structural changes in the renal and cardiovascular systems [34-36, 62].

\section{Premature senescence}

Many conditions related to patterns of early growth are traditionally associated with aging. Therefore, one plausible mechanism could be premature senescence at the cellular level [41]. Cell senescence is a condition of growth arrest caused by increases in the cell-cycle inhibitors p53, p21 and p16. Progressive telomere shortening and DNA damage from various insults can activate the upregulation of the genes coding for these proteins [69]. In experimental models, rapid postnatal weight gain in LBW is associated with shorter telomeres and an increased expression of senescence markers in the kidneys, heart and aorta, as well as premature death, which all fit with a scenario of accelerated premature aging [70, 71]. Premature senescence in the kidney may result from ongoing hyperfiltration injury with a few nephrons, accompanied by a rapid increase in body size [12]. In contrast, caloric restriction in normal mice is linked with slower aging, decreased p 16 expression and fewer pathological changes in the kidney and heart [72]. Oxidative stress is also associated with premature senescence. Telomeres are shortened in the presence of oxidative stress [41]. In humans, children born SGA and those who experienced catch-up growth show the highest markers of oxidative stress compared with control subjects [73].
Markers of the mitochondrial production of reactive oxygen species increase in adult kidneys of LBW rats after a period of rapid catch-up growth [71].

\section{Epigenetic changes}

Epigenetics can be characterized by any alteration in phenotype or gene expression caused by modifications other than genotypic changes. These changes include DNA methylation and histone modifications. Emerging evidence suggests that epigenetic changes form important underlying mechanisms in early life programming [74]. Numerous epigenetic alterations occur in models of programmed HTN within regulatory regions of genes affecting the hypothalamic-pituitary-adrenal axis [75]. Juvenile IUGR rats show renal p53 hypomethylation in association with increased p53 mRNA and renal apoptosis, as well as a resulting loss in glomeruli [76]. Maternal dietary protein restriction during pregnancy also reduces methylation of peroxisome proliferator-activated receptor $\alpha$ and glucocorticoid receptor genes in the liver of offspring after weaning [77]. These genes affect carbohydrate and lipid metabolism and could have an impact on glucose homeostasis and adiposity, possibly increasing the risk of insulin resistance, type 2 diabetes and obesity, which are all key factors in the onset of CKD and CVD [74]. The RAS is also presumed to be vulnerable to this epigenetic change, and the ability of angiotensin II to induce renal branching morphogenesis is epigenetically regulated via histone deacetylase activity [78]. Further research on epigenetic alterations during early growth, particularly on genes affecting renal development, is necessary to understand the fundamental mechanisms of developmental programming of CKD. 
Acknowledgments This work was supported by the Korea Research Foundation Grant funded by the Korean Government (KRF-2008-313E00308) and by the Basic Science Research Program through the National Research Foundation of Korea funded by the Ministry of Education, Science and Technology (20100007640).

\section{Key summary points}

1. Low birth weight, decreased nephron number and perinatal RAS system alterations increase the risk of HTN and renal disease in later life.

2. Perinatally acquired obesity and its complications can be transmitted to succeeding generations, indicating a multiplication of programmed effects.

3. High birth weight, maternal diabetes and accelerated postnatal growth are risk factors for the future development of obesity, type 2 diabetes, CVD and CKD.

4. Excessive weight gain in the early stages of life may increase the susceptibility to the future development of $\mathrm{CKD}$, independent of birth weight.

\section{Multiple choice questions (answers are provided just preceding the reference list)}

1. The kidney can be programmed by:
a. Birth weight
b. Renal sympathetic nerves
c. Renin-angiotensin system
d. All of the above

2. A decreased nephron number causes:
a. Increase in the filtration surface area
b. Glomerular hypertrophy
c. Decrease in stroke volume
d. Decrease in BP levels

3. Rapid postnatal growth during early life is associated with:
a. Hyperphagia
b. Leptin resistance
c. Hyperinsulinemia
d. All of the above

4. Early postnatal overnutrition may affect renal dysfunction in later life by:
a. Preventing apoptosis
b. Increasing telomere length

c Promoting glomerular filtration per nephron

d Decreasing reactive oxygen species production

5. The RAS may affect renal programming by:
a. Increasing inflammatory cell infiltration
b. Decreasing cell hypertrophy
c. Inhibiting cell apoptosis
d. All of the above

\section{References}

1. Flynn MA, McNeil DA, Maloff B, Mutasingwa D, Wu M, Ford C, Tough SC (2006) Reducing obesity and related chronic disease risk in children and youth: a synthesis of evidence with 'best practice' recommendations. Obes Rev 7:7-66

2. Ting SM, Nair H, Ching I, Taheri S, Dasgupta I (2009) Overweight, obesity and chronic kidney disease. Nephron Clin Pract 112:121-127

3. Tonelli M, Wiebe N, Culleton B, House A, Rabbat C, Fok M, McAlister F, Garg AX (2006) Chronic kidney disease and mortality risk: a systematic review. J Am Soc Nephrol 17:2034-2047

4. Hanson M, Gluckman P (2011) Developmental origins of noncommunicable disease: population and public health implications. Am J Clin Nutr 94:1754S-1758S

5. Barker DJ, Winter PD, Osmond C, Margetts B, Simmons SJ (1989) Weight in infancy and death from ischaemic heart disease. Lancet 2: $577-580$

6. Curhan GC, Willett WC, Rimm EB, Spiegelman D, Ascherio AL, Stampfer MJ (1996) Birth weight and adult hypertension, diabetes mellitus, and obesity in US men. Circulation 94:3246-3250

7. Law CM, Shiell AW, Newsome CA, Syddall HE, Shinebourne EA, Fayers PM, Martyn CN, de Swiet M (2002) Fetal, infant, and childhood growth and adult blood pressure: a longitudinal study from birth to 22 years of age. Circulation 105:1088-1092

8. Plagemann A, Harder T, Rake A, Voits M, Fink H, Rohde W, Dörner G (1999) Perinatal elevation of hypothalamic insulin, acquired malformation of hypothalamic galaninergic neurons, and syndrome $\mathrm{x}-$ like alterations in adulthood of neonatally overfed rats. Brain Res 836:146-155

9. Stettler N, Stallings VA, Troxel AB, Zhao J, Schinnar R, Nelson SE, Ziegler EE, Strom BL (2005) Weight gain in the first week of life and overweight in adulthood: a cohort study of European American subjects fed infant formula. Circulation 111:897-1903

10. Habbout A, Li N, Rochette L, Vergely C (2013) Postnatal overfeeding in rodents by litter size reduction induces major short- and longterm pathophysiological consequences. J Nutr 143:553-562

11. Hinchliffe SA, Sargent PH, Howard CV, Chan YF, van Velzen D (1991) The effect of intrauterine growth expressed in absolute number of glomeruli assessed by the "disector" method and Cavalieri principle. Lab Invest 64:777-784

12. Luyckx VA, Bertram JF, Brenner BM, Fall C, Hoy WE, Ozanne SE, Vikse BE (2013) Effect of fetal and child health on kidney development and long-term risk of hypertension and kidney disease. Lancet 382:273-283

13. Lelièvre-Pégorier M, Merlet-Bénichou C (2000) The number of nephrons in the mammalian kidney: environmental influences play a determining role. Exp Nephrol 8:63-65

14. Simeoni U, Ligi I, Buffat C, Boubred F (2011) Adverse consequences of accelerated neonatal growth: cardiovascular and renal issues. Pediatr Nephrol 26:493-508 
15. Aperia A, Broberger O, Herin P, Thodenius K, Zetterstrom R (1983) Postnatal control of water and electrolyte homeostasis in pre-term and full-term infants. Acta Paediatr Scand Suppl 305:61-65

16. Holtback U, Aperia AC (2003) Molecular determinants of sodium and water balance during early human development. Semin Neonatol 8:291-299

17. Wlodek ME, Mibus A, Tan A, Siebel AL, Owens JA, Moritz KM (2007) Normal lactational environment restores nephron endowment and prevents hypertension after placental restriction in the rat. J Am Soc Nephrol 18:1688-1696

18. Kett MM, Denton KM (2011) Renal programming: cause for concern? Am J Physiol Regul Integr Comp Physiol 300:791-803

19. Brenner BM, Garcia DL, Anderson S (1988) Glomeruli and blood pressure: less of one, more the other? Am J Hypertens 1:335-347

20. Martins JP, Monteiro JC, Paixão AD (2003) Renal function in adult rats subjected to prenatal dexamethasone. Clin Exp Pharmacol Physiol 30:32-37

21. Simeoni U, Barker DJ (2009) Offspring of diabetic pregnancy: longterm outcomes. Semin Fetal Neonatal Med 14:119-124

22. Hinchliffe SA, Lynch MR, Sargent PH, Howard CV, Van Velzen D (1992) The effect of intrauterine growth retardation on the development of renal nephrons. Br J Obstet Gynaecol 99:296-301

23. Hughson M, Farris AB 3rd, Douglas-Denton R, Hoy WE, Bertram JF (2003) Glomerular number and size in autopsy kidneys: the relationship to birth weight. Kidney Int 63:2113-2122

24. Boubred F, Saint-Faust M, Buffat C, Ligi I, Grandvuillemin I, Simeoni U (2013) Developmental origins of chronic renal disease: an integrative hypothesis. Int J Nephrol 2013:346067

25. Kreutz R, Kovacevic L, Schulz A, Rothermund L, Ketteler M, Paul M (2000) Effect of high $\mathrm{NaCl}$ diet on spontaneous hypertension in a genetic rat model with reduced nephron number. J Hypertens 18: 777-782

26. Schütz S, Le Moullec JM, Corvol P, Gasc JM (1996) Early expression of all the components of the renin-angiotensin-system in human development. Am J Pathol 149:2067-2079

27. Guron G, Friberg P (2000) An intact renin-angiotensin system is a prerequisite for normal renal development. J Hypertens 18:123-137

28. Yoo KH, Wolstenholme JT, Chevalier RL (1997) Angiotensinconverting enzyme inhibition decreases growth factor expression in the neonatal rat kidney. Pediatr Res 42:588-592

29. Yim HE, Yoo KH, Bae IS, Jang GY, Hong YS, Lee JW (2009) Aldosterone regulates cellular turnover and mitogen-activated protein kinase family expression in the neonatal rat kidney. J Cell Physiol 219:724-733

30. Choi JH, Yoo KH, Cheon HW, Kim KB, Hong YS, Lee JW, Kim SK, Kim CH (2002) Angiotensin converting enzyme inhibition decreases cell turnover in the neonatal rat heart. Pediatr Res 52:325-332

31. Vehaskari VM, Stewart T, Lafont D, Soyez C, Seth D, Manning J (2004) Kidney angiotensin and angiotensin receptor expression in prenatally programmed hypertension. Am J Physiol Renal Physiol 287:262-267

32. Woods LL, Ingelfinger JR, Nyengaard JR, Rasch R (2001) Maternal protein restriction suppresses the newborn renin-angiotensin system and programs adult hypertension in rats. Pediatr Res 49:460-467

33. Machado FG, Poppi EP, Fanelli C, Malheiros DM, Zatz R, Fujihara CK (2008) AT1 blockade during lactation as a model of chronic nephropathy: mechanisms of renal injury. Am J Physiol Renal Physiol 294:1345-1353

34. Yim HE, Ha KS, Bae IS, Yoo KH, Hong YS, Lee JW (2012) Postnatal early over nutrition dysregulates the intrarenal reninangiotensin system and extracellular matrix-linked molecules in juvenile male rats. J Nutr Biochem 23:937-945

35. Yim HE, Ha KS, Bae IS, Yoo KH, Hong YS, Lee JW (2013) Overweight, hypertension and renal dysfunction in adulthood of neonatally overfed rats. J Nutr Biochem 24:1324-1333
36. Yim HE, Yoo KH, Bae IS, Hong YS, Lee JW (2014) Postnatal early over nutrition causes a long-term renal decline in aging male rats. Pediatr Res 75:259-265

37. Spencer SJ (2012) Early life programming of obesity: the impact of the perinatal environment on the development of obesity and metabolic dysfunction in the offspring. Curr Diabetes Rev 8:55-68

38. Ravelli GP, Stein ZA, Susser MW (1976) Obesity in young men after famine exposure in utero and early infancy. N Engl J Med 295:349-353

39. Desai M, Gayle D, Babu J, Ross MG (2005) Programmed obesity in intrauterine growth-restricted newborns: modulation by newborn nutrition. Am J Physiol Regul Integr Comp Physiol 288:91-96

40. Ross MG, Desai M (2005) Gestational programming: population survival effects of drought and famine during pregnancy. Am J Physiol Regul Integr Comp Physiol 288:25-33

41. Tarry-Adkins JL, Ozanne SE (2011) Mechanisms of early life programming: current knowledge and future directions. Am J Clin Nutr 94:1765-1771

42. Catalano PM, Eherberg HM (2006) The short and long-term implications of maternal obesity on the mother and her offspring. BJOG 113:1126-1133

43. McCance DR, Pettitt DJ, Hanson RL, Jacobsson LT, Knowler WC, Bennett PH (1994) Birth weight and non-insulin dependent diabetes: thrifty genotype, thrifty phenotype, or surviving small baby genotype? BMJ 308:942-945

44. Silverman BL, Rizzo TA, Cho NH, Metzger BE (1998) Long-term effects of the intrauterine environment.The Northwestern University diabetes in pregnancy center. Long-term effects of the intrauterine environment. Diabetes Care 21:142-149

45. Pettitt DJ, Baird HR, Aleck KA, Bennett PH, Knowler WC (1983) Excessive obesity in offspring of Pima Indian women with diabetes during pregnancy. N Engl J Med 308:242-245

46. Fraser A, Tilling K, Macdonald-Wallis C, Sattar N, Brion MJ, Benfield L, Ness A, Deanfield J, Hingorani A, Nelson SM, Smith GD, Lawlor DA (2010) Association of maternal weight gain in pregnancy with offspring obesity and metabolic and vascular traits in childhood. Circulation 121:2557-2564

47. Boney CM, Verma A, Tucker R, Vohr BR (2005) Metabolic syndrome in childhood: association with birth weight, maternal obesity and gestational diabetes mellitus. Pediatrics 115:290-296

48. Catalano PM, Farrell K, Thomas A, Huston-Presley L, Mencin P, de Mouzon SH, Amini SB (2009) Perinatal risk factors for childhood obesity and metabolic dysregulation. Am J Clin Nutr 90:1303-1313

49. Plagemann A (2005) Perinatal programming and functional teratogenesis: impact on body weight regulation and obesity. Physiol Behav 86:661-668

50. Kelishadi R, Poursafa P (2014) A review on the genetic, environmental, and lifestyle aspects of the early-life origins of cardiovascular disease. Curr Probl Pediatr Adolesc Health Care 44:54-72

51. Tzoulaki I, Sovio U, Pillas D, Hartikainen AL, Pouta A, Laitinen J, Tammelin TH, Jarvelin MR, Elliott P (2010) Relation of immediate postnatal growth with obesity and related metabolic risk factors in adulthood: the northern Finland birth cohort 1966 study. Am J Epidemiol 171:989-998

52. Boubred F, Daniel L, Buffat C, Feuerstein JM, Tsimaratos M, Oliver C, Dignat-George F, Lelièvre-Pégorier M, Simeoni U (2009) Early postnatal overfeeding induces early chronic renal dysfunction in adult male rats. Am J Physiol Renal Physiol 297:943-951

53. Li S, Chen SC, Shlipak M, Bakris G, McCullough PA, Sowers J, Stevens L, Jurkovitz C, McFarlane S, Norris K, Vassalotti J, Klag MJ, Brown WW, Narva A, Calhoun D, Johnson B, Obialo C, WhaleyConnell A, Becker B, Collins AJ, Kidney Early Evaluation Program Investigators (2008) Low birth weight is associated with chronic kidney disease only in men. Kidney Int 73:637-642

54. Vikse BE, Irgens LM, Leivestad T, Hallan S, Iversen BM (2008) Low birth weight increases risk for end-stage renal disease. J Am Soc Nephrol 19:151-157 
55. Stene LC, Magnus P, Lie RT, Sovik O, Joner G, Norwegian childhood Diabetes Study Group (2001) Birth weight and childhood onset type 1 diabetes: population based cohort study. BMJ 322:889-892

56. Andersen LG, Angquist L, Eriksson JG, Forsen T, Gamborg M, Osmond C, Baker JL, Sørensen TI (2010) Birth weight, childhood body mass index and risk of coronary heart disease in adults: combined historical cohort studies. PLoS One 5:e14126

57. Abitbol CL, Chandar J, Rodríguez MM, Berho M, Seeherunvong W, Freundlich M, Zilleruelo G (2009) Obesity and preterm birth: additive risks in the progression of kidney disease in children. Pediatr Nephrol 24:1363-1370

58. Schmidt IM, Damgaard IN, Boisen KA, Mau C, Chellakooty M, Olgaard K, Main KM (2004) Increased kidney growth in formula-fed versus breast-fed healthy infants. Pediatr Nephrol 19:1137-1144

59. Escribano J, Luque V, Ferre N, Zaragoza-Jordana M, Grote V, Koletzko B, Gruszfeld D, Socha P, Dain E, Van Hees JN, Verduci E, Closa-Monasterolo R (2011) Increased protein intake augments kidney volume and function in healthy infants. Kidney Int 79:783-790

60. Silverwood RJ, Pierce M, Hardy R, Thomas C, Ferro C, Savage C, Sattar N, Kuh D, Nitsch D, National Survey of Health and Development Scientific and Data Collection Teams (2013) Earlylife overweight trajectory and CKD in the 1946 British Birth Cohort study. Am J Kidney Dis 62:276-284

61. Samuelsson AM, Matthews PA, Argenton M, Christie MR, McConnell JM, Jansen EH, Piersma AH, Ozanne SE, Twinn DF, Remacle C, Rowlerson A, Poston L, Taylor PD (2008) Diet induced obesity in female mice leads to offspring hyperphagia, adiposity, hypertension and insulin resistance: a novel murine model of developmental programming. Hypertension 51:383-392

62. Ha KS, Yoo KH, Yim HE, Jang GY, Bae IS, Hong YS, Lee JW (2011) Cellular and RAS changes in the hearts of young obese rats. Pediatr Cardiol 32:659-666

63. Moreira AS, Teixeira M, da Silveira OF, Pereira RO, de Oliveira SJG, Garcia de Souza EP, Mandarim de Lacerda CA, Moura AS (2009) Left ventricular hypertrophy induced by over nutrition early in life. Nutr Metab Cardiovasc Dis 19:805-810

64. Alcazar MA, Boehler E, Rother E, Amann K, Vohlen C, von Horsten S, Plank C, Dotsch J (2012) Early postnatal hyper alimentation impairs renal function via SOCS-3 mediated renal postreceptor leptin resistance. Endocrinology 153:1397-1410

65. Michel MC, Rascher W (1995) Neuropeptide Y: a possible role in hypertension? J Hypertens 13:385-395

66. Habbout A, Guenancia C, Lorin J, Rigal E, Fassot C, Rochette L, Vergely C (2013) Postnatal overfeeding causes early heart-gene expression shifts and long-term cardiometabolic and oxidative alterations. PLoS One 8:e56981

67. Velkoska E, Cole TJ, Dean RG, Burrell LM, Morris MJ (2008) Early undernutrition leads to long-lasting reductions in body weight and adiposity whereas increased intake increases cardiac fibrosis in male rats. J Nutr 138:1622-1627

68. Garofano A, Czernichow P, Breant B (1999) Effect of ageing on betacell mass and function in rats malnourished during the perinatal period. Diabetologia 42:711-718

69. Zhang H (2007) Molecular signaling and genetic pathways of senescence: its role in tumorigenesis and aging. J Cell Physiol 210:567574

70. Ozanne SE, Hales CN (2004) Lifespan: catch-up growth and obesity in male mice. Nature 427:411-412

71. Luyckx VA, Compston CA, Simmen T, Mueller TF (2009) Accelerated senescence in kidneys of low-birth-weight rats after catch-up growth. Am J Physiol Renal Physiol 297:1697-1705

72. Krishnamurthy J, Torrice C, Ramsey MR, Kovalev GI, Al-Regaiey $\mathrm{K}$, Su L, Sharpless NE (2004) Ink4a/Arf expression is a biomarker of aging. J Clin Invest 114:1299-1307

73. Mohn A, Chiavaroli V, Cerruto M, Blasetti A, Giannini C, Bucciarelli $\mathrm{T}$, Chiarelli $\mathrm{F}$ (2007) Increased oxidative stress in prepubertal children born small for gestational age. J Clin Endocrinol Metab 92: 1372-1378

74. O'Sullivan L, Combes AN, Moritz KM (2012) Epigenetics and developmental programming of adult onset diseases. Pediatr Nephrol 27:2175-2182

75. Shaltout HA, Chappell MC, Rose JC, Diz DI (2011) Exaggerated sympathetic mediated responses to behavioral or pharmacological challenges following antenatal betamethasone exposure. Am J Physiol Endocrinol Metab 300:979-985

76. Pham TD, MacLennan NK, Chiu CT, Laksana GS, Hsu JL, Lane RH (2003) Uteroplacental insufficiency increases apoptosis and alters p53 gene methylation in the full-term IUGR rat kidney. Am J Physiol Regul Integr Comp Physiol 285:962-970

77. Lillycrop KA, Phillips ES, Jackson AA, Hanson MA, Burdge GC (2005) Dietary protein restriction of pregnant rats induces and folic acid supplementation prevents epigenetic modification of hepatic gene expression in the offspring. J Nutr 135:1382-1386

78. Song R, Van Buren T, Yosypiv IV (2010) Histone deacetylases are critical regulators of the renin-angiotensin system during ureteric bud branching morphogenesis. Pediatr Res 67:573-578

\section{Answers to questions}

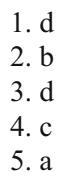

